\title{
HUMAN C7 POLYMORPHISM: CLASSIFICATION AND ASSOCIATION ANALYSIS WITH C6
}

\author{
Keiko Washio, ${ }^{1}$ Katsushi ToKunaga, ${ }^{2}$ Keiichi Oмото, ${ }^{2}$ \\ and Shogo MISAWA ${ }^{1}$ \\ ${ }^{1}$ Department of Legal Medicine, Institute of Community Medicine, University \\ of Tsukuba, Niihari-gun, Ibaraki 305, Japan \\ 'Department of Anthropology, Faculty of Science, The University of Tokyo, \\ Hongo, Bunkyo-ku, Tokyo 113, Japan
}

\begin{abstract}
Summary Polymorphism of the seventh component of human complement (C7) was investigated in Japanese. Four common and one rare allotypes were observed with desialized samples. Besides three common alleles, $C 7^{*} 1, C 7^{*} 2$ and $C 7^{*} 4$, the existence of the hypomorphic variant, $C 7^{*} 3$, was confirmed in Japanese with a polymorphic frequency. The recently described $C 7^{*} 5$ was found to correspond to $C 7^{*} 3$ by comparing with reference samples. Moreover, a rare variant, tentatively named $\mathrm{C} 7 \mathrm{7}$, was considered to be new. The population samples were also typed for C6. A rare variant, designated $\mathrm{M} 92$, was newly found. No significant associations between $\mathrm{C} 6$ and $\mathrm{C} 7$ alleles were found.
\end{abstract}

\section{INTRODUCTION}

The sixth component (C6) and the seventh component (C7) of the complement system participate in the formation of the membrane attack complex against microorganisms. Genetic polymorphism of $\mathrm{C} 7$ was first discovered by Hobart et al. (1978) using polyacrylamide gel isoelectric focusing and a hemolytic detection. A common allele, $C 7^{*} 1$, and two rare alleles, $C 7^{*} 2$ and $C 7 * 3$ at a single autosomal locus were recognized in Caucasians. In Japanese, three alleles were detected with frequencies more than 0.01 , using polyacrylamide gel isoelectric focusing and an immunoblotting method (Nakamura et al., 1984a). The three common allotypes were identified to be C7 1, C7 2 and C7 4, respectively (Tokunaga et al., 1986). Recently, Nishimukai and Tamaki (1986) reported another variant, which showed more basic bands than $\mathrm{C} 7 \mathrm{1}$ after treatment with neuraminidase, and designated C7 5. They observed a high frequency of $C 7 * 5(0.049)$ in a western Japanese population and suggested the lower protein concentration of $C 7 * 5$ products than those of the other alleles.

Received August 11, 1986; Accepted September 19, 1986 
Genetic polymorphism of $\mathrm{C} 6$ has been investigated in many ethnic groups. Two common alleles, $C 6^{*} A$ and $C 6^{*} B$, and several rare variants at a single autosomal locus have been described in Caucasians using prolonged agarose gel electrophoresis or polyacrylamide gel isoelectric focusing followed by hemolytic overlay (Hobart et al., 1975; Mauff et al., 1980). Whitehouse and Putt (1983) applied an immunoblotting procedure, involving electrophoretic protein transfer, in order to obtain $\mathrm{C} 6$ patterns after isoelectric focusing. In Japanese, the third common allele, $C \sigma^{*} B 2$, and many rare variants have been detected using isoelectric focusing in polyacrylamide gel or agarose gel followed by hemolytic overlay or immunoblotting (Tokunaga et al., 1983, 1984; Nishimukai et al., 1985).

C6 and $\mathrm{C} 7$ are single chain glycoproteins, and show functional and physicochemical similarities to each other (Podack et al., 1976). The close linkage of the structural loci for C6 and C7 has been confirmed (Tokunaga et al., 1986; Lachmann et al., 1978), although the chromosomal location of the loci is still unknown (Olving et al., 1979; Bender et al., 1983).

Nakamura et al. (1984b) reported positive associations of $C 6^{*} B$ with $C 7^{*} B$ $\left(=C 7^{*} I\right)$ and $C 6^{*} M$ with $C 7^{*} B$ from the population data. On the contrary, Tokunaga et al. (1986) could not find linkage disequilibrium between any $C 6$ and C7 alleles in an extensive family study. Nishimukai and Tamaki (1986) also described no significant positive association in a population analysis.

The purpose of the present study is to investigate $\mathrm{C} 7$ polymorphism in an eastern Japanese population and to analyze possible associations between $\mathrm{C} 6$ and $\mathrm{C} 7$ alleles. Moreover, correspondence between C7 5 by Nishimukai and Tamaki (1986) and C7 3 by Hobart et al. (1978) is reported. Two newly observed variants are also described.

\section{MATERIALS AND METHODS}

A total of 351 ACD-plasma samples were obtained from healthy blood donors living in an eastern area of Japan, Ibaraki prefecture. Plasma samples were stored at $-30^{\circ} \mathrm{C}$ for up to a few months before typing. For C7 typing, 217 samples out of 351 were treated with $5 \mathrm{U} / \mathrm{ml}$ neuraminidase (type V, Sigma, U.S.A.) at room temperature overnight, as described for C4 typing (Mauff et al., 1983). All native plasma samples were phenotyped for $\mathrm{C} 6$.

Phenotypings of $\mathrm{C} 7$ and $\mathrm{C} 6$ were performed using isoelectric focusing in polyacrylamide gel and immanoblotting procedure (Tokunaga et al., 1984, 1986) with slight modifications as follows: Polyvinyden fluoride filter (Durapore, $0.22 \mu \mathrm{m}$, Millipore, U.S.A.) was used instead of the nitrocellulose filter because of its durability and an increasing efficiency for protein transfer. The hydrophobic filter was first treated with methyl-alcohol and then soaked in phosphate buffered saline (PBS). For the protein transfer by a 'press blotting,' the filter was directly layered on the polyacrylamide gel after focusing, followed by pressing with two filter papers, several 
paper towels, and approximately $500 \mathrm{~g}$ weight for $30 \mathrm{~min}$. The filter was easily separated from the gel in PBS.

Association analysis between $\mathrm{C} 6$ and $\mathrm{C} 7$ alleles was performed in $2 \times 2$ tables by chi-square statistics.

\section{RESULTS}

\section{C7 polymorphism}

The patterns of desialized $\mathrm{C} 7$ obtained from 217 samples are presented in Fig. 1. Nine different phenotypes were observed, in which four common and one rare allotypes were distinguished. Three common allotypes have been identified as C7 1, 2 and 4, respectively (Tokunaga et al., 1986). The fourth common allotype, showing a weak major band more basic than that of $\mathrm{C} 71$ after neuraminidase-treatment, was previously named C7 5 by Nishimukai and Tamaki (1986). The variant samples found in this study and those from Caucasians were exchanged with Dr. Lachmann (MRC Group on Mechanisms in Tumour Immunity Unit, Cambridge). As the result of reference typing, the fourth common variant could not be distinguished from the hypomorphic variant, C7 3 (Hobart et al., 1978) both in native and in neuraminidase-treated samples.

A rare variant, which showed the major band between those of C7 2 and C7 4, was different from any other variant. The variant was considered to be new, and tentatively named $\mathrm{C} 77$. The results of $\mathrm{C} 7$ phenotyping and allele frequencies are shown in Table 1. The allele frequencies estimated for $C 7^{*} 1, C 7^{*} 2, C 7^{*} 3, C 7^{*} 4$ and $C 7 * 7$ are $0.813,0.097,0.037,0.051$ and 0.002 , respectively. The deviation of

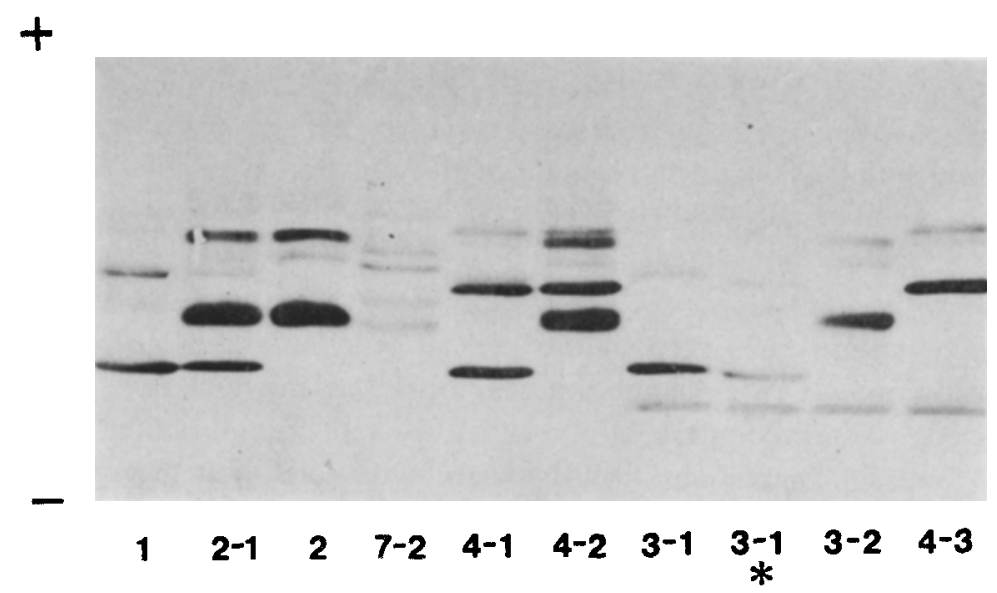

Fig. 1. Patterns of $\mathrm{C7}$ phenotypes obtained from neuraminidase-treated samples by isoelectric focusing and immunoblotting. * Reference sample provided by Dr. P.J. Lachmann. 
Table 1. Distribution of $\mathrm{C} 7$ phenotypes and allele frequencies.

\begin{tabular}{ccccc}
\hline Phenotypes & $\begin{array}{c}\text { No. } \\
\text { observed }\end{array}$ & $\%$ & $\begin{array}{c}\text { No. } \\
\text { expected }\end{array}$ & Allele frequencies \\
\hline 1 & 148 & 68.2 & 143.4 & $C 7^{*} I=0.813$ \\
$2-1$ & 26 & 12.0 & 34.2 & $C 7^{*} 2=0.097$ \\
$3-1$ & 13 & 6.0 & 13.0 & \\
$4-1$ & 18 & 8.3 & 18.0 & $C 7^{*} 3=0.037$ \\
2 & 5 & 2.3 & 2.0 & $C 7^{*} 4=0.051$ \\
$3-2$ & 2 & 0.9 & 1.6 & $C 7^{*} 7=0.002$ \\
$4-2$ & 3 & 1.4 & 2.1 & 1.000 \\
Others $^{a}$ & 2 & 0.9 & 2.7 & \\
Total $^{2}$ & 217 & 100.0 & 217.0 & \\
\hline
\end{tabular}

a Others: C7 4-3, C7 7-2. $\chi^{2}=7.28$, d.f. $=5,0.20<\mathrm{p}<0.30$.

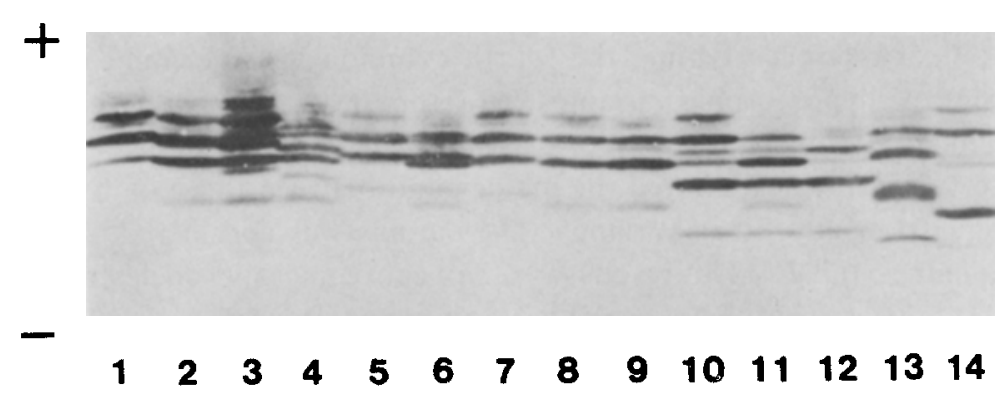

Fig. 2. Patterns of $\mathrm{C} 6$ phenotypes obtained by isoelectric focusing and immunoblotting.

(1) C6 A, (2) C6 M92B, (3) C6 M91B, (4) C6 M1B, (5) C6 AM11, (6) C6 M11B,

(7) $\mathrm{C} 6 \mathrm{AM} 2,(8) \mathrm{C} 6 \mathrm{AB}$, (9) $\mathrm{C} 6 \mathrm{~B},(10) \mathrm{C} 6 \mathrm{AB} 2,(11) \mathrm{C} 6 \mathrm{BB} 2,(12) \mathrm{C} 6 \mathrm{~B} 2,(13) \mathrm{C} 6$

$\mathrm{BB} 3$, (14) C6 AB4. (3), (4) and (13) are reference samples.

the observed numbers of phenotypes from those expected on the Hardy-Weinberg equilibrium is statistically non-significant $\left(\chi^{2}=7.28\right.$, d.f $\left.=5,0.20<p<0.30\right)$.

\section{C6 polymorphism}

The C6 patterns observed in the present study are demonstrated in Fig. 2. Five common and six rare phenotypes were observed, in which seven allotypes were distinguished. Three common allotypes, A, B and B2, and three rare allotypes, .M11, M2 and B4, were identified, by direct comparison with reference samples (Tokunaga et al., 1983, 1984). Another variant shows the bands very close to C6 A bands, but slightly more basic than $\mathrm{C} 6 \mathrm{~A}$. Because the variant bands were more acidic than M91 bands (formerly 91, Tokunaga et al., 1984) and was considered to be different from any variant previously described, it was designated M92. Distribution of $\mathrm{C} 6$ phenotypes and allele frequencies are shown in Table 2. The allele 
Table 2. Distribution of $\mathrm{C} 6$ phenotypes and allele frequencies.

\begin{tabular}{|c|c|c|c|c|}
\hline Phenotypes & $\begin{array}{c}\text { No. } \\
\text { observed }\end{array}$ & $\%$ & $\begin{array}{l}\text { No. } \\
\text { expected }\end{array}$ & Allele frequencies \\
\hline$A$ & 64 & 18.2 & 71.1 & $C 6^{*} A=0.450$ \\
\hline $\mathrm{AB}$ & 164 & 46.7 & 150.8 & \\
\hline$B$ & 75 & 21.4 & 79.9 & $C 6^{*} B=0.477$ \\
\hline $\mathrm{AB} 2$ & 20 & 5.7 & 20.2 & \\
\hline $\mathrm{BB} 2$ & 19 & 5.4 & 21.4 & $C 6^{*} B 2=0.064$ \\
\hline $\mathrm{B} 2$ & 3 & 0.9 & 1.4 & \\
\hline $\mathrm{AR}^{\mathrm{a}}$ & 4 & 1.1 & 2.8 & $C 6^{*} R=0.009$ \\
\hline $\mathrm{BR}^{\mathrm{a}}$ & 2 & 0.6 & 3.0 & \\
\hline Others & 0 & 0.0 & 0.4 & \\
\hline Total & 351 & 100.0 & 351.0 & 1.000 \\
\hline
\end{tabular}

Table 3. Association analysis between $\mathrm{C} 6$ and $\mathrm{C} 7$ alleles.

\begin{tabular}{|c|c|c|c|c|c|c|}
\hline Combinations $^{2}$ & $+1+$ & $+1-$ & $-1+$ & $-1-$ & $\chi^{2}$ & $p$ \\
\hline$C 6^{*} A-C 7^{*} I$ & 148 & 10 & 57 & 2 & 0.710 & NS \\
\hline$C 6^{*} A-C 7^{*} 2$ & 28 & 130 & 9 & 50 & 0.185 & NS \\
\hline$C 6^{*} A-C 7^{*} 3$ & 10 & 148 & 6 & 53 & 0.928 & NS \\
\hline$C 6^{*} A-C 7^{*} 4$ & 16 & 142 & 6 & 53 & 0.000 & NS \\
\hline$C 6^{*} B-C 7^{*} 1$ & 157 & 11 & 48 & 1 & 1.475 & NS \\
\hline$C 6^{*} B-C 7^{*} 2$ & 31 & 137 & 6 & 43 & 1.034 & NS \\
\hline$C 6^{*} B-C 7^{*} 3$ & 13 & 155 & 3 & 46 & 0.145 & NS \\
\hline$C 6^{*} B-C 7^{*} 4$ & 20 & 148 & 2 & 47 & 0.200 & NS \\
\hline$C 6^{*} B 2-C 7^{*} I$ & 20 & 1 & 185 & 11 & 0.026 & NS \\
\hline$C 6^{*} B 2-C 7^{* 2}$ & 4 & 17 & 33 & 163 & 0.066 & NS \\
\hline$C 6^{*} R-C 7^{*} I$ & 5 & 0 & 203 & 9 & 0.169 & NS \\
\hline
\end{tabular}

a Only the combinations in which the incidence of the $+1+$ individuals exceeding 0.01 are given.

b NS, not significant.

frequencies estimated for $C 6^{*} A, C 6^{*} B, C 6^{*} B 2$ and the rare variants are $0.450,0.477$, 0.064 and 0.009 , respectively. The observed numbers of the phenotypes are distributed in accordance with Hardy-Weinberg law $\left(\chi^{2}=4.96\right.$, d.f. $\left.=5,0.30<p<0.50\right)$.

Association analysis between $C 6$ and $C 7$

Analysis on the possible associations between $\mathrm{C} 6$ and $\mathrm{C} 7$ alleles was performed in 217 samples (Table 3). No significant associations were found. 


\section{DISCUSSION}

Recently, Nishimukai and Tamaki (1986) proposed a new allotype C7 5, using agarose gel isoelectric focusing followed by immunobotting with desialized samples. They also presented pedigrees indicating the inheritance of the $C 75$. In the present study, we confirmed that the C7 5 reported by Nishimukai and Tamaki corresponds to the C7 3 described by Hobart et al. (1978). The same conclusion was also obtained by Drs. M.J. Hobart and P.J. Lachmann (Cambridge, UK, personal communication). Interestingly, $C 7^{*} 3$ exists at a polymorphic frequency in Japanese, in spite of the finding that the protein concentration of C7 3 may be lower than those of the other allotypes (Hobart et al., 1978; Nishimukai and Tamaki, 1986). We consider that samples should be desialized prior to $\mathrm{C} 7$ typing by immunoblotting. Without neuraminidase-treatment, $\mathrm{C} 73$ bands may be difficult to distinguish from the minor bands of the other allotypes or non-specific bands in the immunoblotting detection.

Moreover, a rare variant, tentatively named $\mathrm{C} 77$, was newly found. Recently another rare variant was found in a Chinese population and was tentatively named C7 6 (Zeng et al., 1986). The C7 frequencies observed in the present material from eastern Japan were statistically not significantly different from those in western part of Japan (Nishimukai et al., 1986).

The allele frequencies of $\mathrm{C} 6$ estimated in the present study are similar to those of the other Japanese populations (Tokunaga et al., 1983, 1984; Nishimukai et al., 1985; Nakamura et al., 1984b). We confirmed that $C 6^{*} B$ is more common than $C 6^{*} A$ and that $C 6^{*} B 2$ is the third common allele in Japanese. A rare variant, $C 6^{*} M 92$, was newly found. The variant was also found in a family samples from Tokyo, which have been collected for the other project. The pedigree shows the inheritance of $\mathrm{C}^{*} \mathrm{M} 92$ as well as $C 7 * 3$ (Fig. 3).

The present study showed no significant association between $\mathrm{C} 6$ and $\mathrm{C} 7$ alleles,

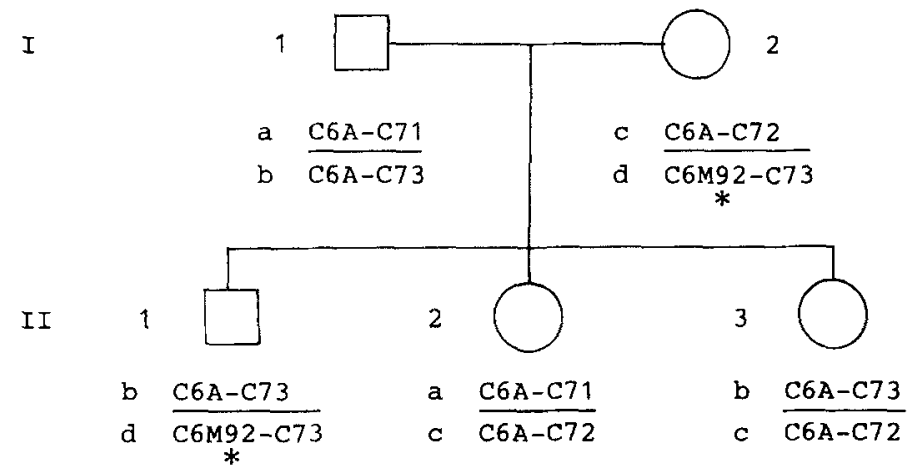

Fig. 3. Pedigree of the family $O N G$ showing the cosegregation of $C 6^{*} M 92$ and $C 7^{*} 3$. 
including $\mathrm{C}^{*} 3$. The result in addition to the previous reports (Tokunaga et al, 1986; Nishimukai and Tamaki, 1986) support that there is no linkage disequilibrium between $\mathrm{C} 6$ and $\mathrm{C} 7$ loci.

Extensive studies on genetic polymorphism of $\mathrm{C} 7$ in various human populations would be expected, because the frequencies of $C 7^{*} 2, C 7^{*} 3$ and $C 7^{*} 4$ are high in Japanese, while they are low in Caucasians. It is interesting that in Japanese, both $\mathrm{C} 6$ and $\mathrm{C} 7$ show higher degree of polymorphism than in Caucasians.

Acknowledgment We thank Dr. M.J. Hobart and Prof. P.J. Lachmann (MRC Group on Mechanisms in Tumour Immunity Unit, Cambridge) for reference typing and sending us the reference samples.

\section{REFERENCES}

Bender, K., Bissbort, S., Mayerová, A., Mauff, G., and Wienker, T.F. 1983. C6 linkage studies. J. Immunogenet. 10:61-67.

Hobart, M.J., Lachmann, P.J., and Alper, C.A. 1975. Polymorphism of human C6. In 22nd Colloquim Brugge 1974, Protides of the Biological Fluids, Pergamon Press, Oxford, pp. 575580.

Hobart, M.J., Joysey, V., and Lachmann, P.J. 1978. Inherited structural variation and linkage relationships of C7. J. Immunogenet. 5: 157-163.

Lachmann, P.J., Hobart, M.J., and Woo, P. 1978. Combined genetic deficiency of C6 and C7 in man. Clin. Exp. Immunol. 33: 193-203.

Mauff, G., Alper, Ch.A., Hobart, M., Kühnl, P., Kunstmann, G., Meo, T., Olving, J.H., and Rittner, Ch., 1980. Statement on the nemenclature of human C6 polymorphism. Immunobiology 158: 139-144.

Mauff, G., Alper, Ch.A., Awdeh, Z., Batchelor, J.R., Bertrams. J., Bruun-Petersen, G., Dawkins, R.L., Démant, P., Edwards, J., Grosse-Wilde, H., Hauptmann, G., Klouda, P., Lamm, L., Mollenhauser, E., Nerl, C., Olaisen, B., O'neill, G., Rittner, Ch., Roos, M.H., Skanes, V., Teisberg, P., and Wells, L. 1983. Statement on the nomenclature of human C4 allotypes. Immunobiology 164: 184-191.

Nakamura, S., Ooue, O., and Abe, K. 1984a. Genetic polymorphism of the seventh component of complement in a Japanese population. Hum. Genet. 66: 279-281.

Nakamua, S., Ooue, O., Akiyama, K., and Abe, K. 1984b. Genetic polymorphism of complement C6 and haplotype analysis between $\mathrm{C} 6$ and $\mathrm{C} 7$ in a Japanese population. Hum. Genet. 68: 138-141.

Nishimukai, H., Kitamura, H., and Tamaki, Y. 1985. C6 polymorphism in Japanese: typing by agarose gel isoelectric focusing-immunofixation. Hum. Hered. 35: 30-33.

Nishimukai, H. and Tamaki, Y. 1986. Genetic polymorphism of the seventh component of complement: A new variant. Vox. Sang. 51:60-62.

Olving, J.H., Olaisen, B., Gedde-Dahl, T., Jr., and Teisberg, P. 1979. Genetic linkage relations of the sixth component of complement (C6). Hum. Genet. 46: 181-192.

Podack, E.R., Kolb, W.P., and Müller-Eberhard, H.J. 1976. Purification of the sixth and seventh component of human complement without loss of hemolytic activity. J. Immunol. 116: 263269.

Tokunaga, K., Yukiyama, Y., and Omoto, K. 1983. Polymorphism of the complement component C6 in Japanese. I. Immunogenet. 10: 419-424.

Tokunaga, K., Yamamura, N., and Omoto, K. 1984. An immunoblotting technique for complement C6 typing: three new variants. Jpn. J. Human Genet. 29: 415-419. 
Tokunaga, K., Dewald, G., Omoto, K., and Iuji, T. 1986. Family study on the polymorphisms of the sixth and seventh components ( 6 and $\mathrm{C} 7$ ) of human complement: linkage and haplotype analyses. Am. J. Hum. Genet. 39: 414-419.

Whitehouse, D.B. and Putt, W. 1983. Immunological detection of the sixth complement component (C6) following flat bed polyacrylamide gel isoelectric focusing and electrophoretic transfer to nitrocellulose filters. Ann. Hum. Genet. 47: 1-8.

Zeng, Z., Tokunaga, K., Omoto, K., and Du, C. 1986. Genetic polymorphisms of complement C6 and $\mathrm{C} 7$ in two Chinese populations. Jpn. J. Human Genet. 31: 263-271. 